\title{
METODOLOGIA E PESQUISA NO CAMPO DAS MIGRAÇÕES INTERNAS: um estudo sobre o processo migratório de norte mineiros
}

\author{
Andréa Maria Narciso Rocha De Paula \\ Universidade Estadual de Montes Claros (UNIMONTES) \\ E-mail: andreapirapora@yahoo.com.br \\ Maria Cecília Cordeiro Pires \\ Universidade Estadual de Montes Claros (UNIMONTES) \\ E-mail: mariacecilia1942@hotmail.com \\ Carla Nadinne Souza \\ Universidade Estadual de Montes Claros (UNIMONTES) \\ E-mail: carlanadinnesouza@gmail.com
}

\begin{abstract}
RESUMO
O presente artigo tem como aporte as pesquisas realizadas através do Grupo de Estudos e Pesquisas - Opará/Mutum/CNPq. Nossa proposta é contribuir para o campo de estudos migratórios, dando continuidade aos projetos desenvolvidos no Norte de Minas Gerais, procurando dar visibilidade para o modo de vida dos povos rurais, por meio de uma reflexão acerca dos processos socioculturais que tangem a migração. Com base nos dados recolhidos em trabalhos de campo, realizados no município Norte Mineiro de Porteirinha, propomos compreender a migração como um processo social complexo, a partir dos relatos das famílias que vivem a migração. Utilizamos a metodologia qualitativa, através das técnicas de entrevista em profundidade, observação do cotidiano e do diário de campo. Nosso estudo revela que as famílias camponesas, no município de Porteirinha, desenvolvem formas particulares do fazer migratório, com o intuito de alcançarem a reprodução social.
\end{abstract}

Palavras-chave: Processo Migratório; Metodologia Qualitativa; Norte de Minas Gerais.

\section{METHODOLOGY AND RESEARCH IN THE FIELD OF INTERNAL MIGRATIONS: a study on the migration process of norte mineiros}

\begin{abstract}
The present article is supported by research carried out through the Grupo de Estudos e Pesquisas Opará/Mutum/CNPq. Our proposal is to contribute to the field of migratory studies, giving continuity to the projects developed in the North of Minas Gerais, seeking to give visibility to the way of life of the rural people, through a reflection on the socio-cultural processes that affect migration. Based on the data gathered from fieldwork carried out in the municipality of Norte Mineiro de Porteirinha, we propose to understand migration as a complex social process, based on the reports of the families that live the migration. We use the qualitative methodology, through the techniques of in-depth interview, daily observation and the field diary. Our study reveals that the peasant families, in the municipality of Porteirinha, develop particular forms of migration, in order to achieve social reproduction.
\end{abstract}

Keywords: Migratory Process; Qualitative Methodology; North of Minas Gerais. 


\section{INTRODUÇÃ̃ ${ }^{1}$}

Estudos sobre migração chamam a atenção para a flexibilidade que o conceito pode assumir em determinados contextos sociais e políticos, ganhando maior visibilidade na contemporaneidade. Todavia, apesar da considerável contribuição analítica de estudos já existentes sobre o fenômeno, poucas pesquisas revelam a experiência vivida por migrantes na negociação estabelecida com suas famílias que ficam a esperar nos locais de origem. Neste sentido, com intuito de contribuir para o diálogo acerca das migrações, suas categorias e aplicações, o presente estudo buscou investigar as estratégias de reprodução social desenvolvidas por trabalhadores do Norte de Minas Gerais, abrindo margem para um aspecto que nosso percurso teórico e metodológico nos revela: o quão dinâmico e complexo é o tema, seja em suas diversas formas, definições e opções metodológicas.

Este trabalho apresenta resultados de pesquisas das autoras, fruto da inserção no Grupo Opará/Mutum/CNPq ${ }^{2}$, que tem como objetivo desenvolver estudos e pesquisas sobre o fenômeno migratório e suas interfaces. Dentre seus resultados, construímos ao longo dos anos, um acervo que conta com monografias, dissertações, teses e projetos com esta temática, sob a autoria dos membros da equipe, composta por pesquisadores de áreas interdisciplinares. Nosso anseio é oferecer continuidade aos projetos que vem sendo desenvolvidos desde 2005, procurando contribuir para o conhecimento dos modos de vida dos povos do Norte de Minas Gerais, estudando o ir e vir e os seus processos socioculturais e políticos.

Durante nossa participação nos Projetos de Pesquisa, "Sair, Ficar, Voltar"3 e "Do Sertão Para Outros Mundos", , tivemos a possibilidade de conhecer contextos distintos de migrações; primeiramente, as migrações temporárias para colheitas e plantios no interior de outras regiões brasileiras; posteriormente, as migrações em redes para as cidades e capitais. Dentre os lócus de pesquisa, priorizamos, para este trabalho, o município Norte Mineiro de Porteirinha, onde procuramos compreender a migração como um processo social complexo, que envolve relações sociais, núcleo familiar e a tradicionalidade. Neste sentido, nosso objetivo foi analisar os processos migratórios no município, e aqui trazemos a reflexão desse fenômeno, dialogando com as narrativas colhidas durante a pesquisa de campo, buscando compreender a dinâmica migratória a partir da família, daqueles que vão e dos que ficam. 


\section{METODOLOGIA}

Os trabalhos vinculados ao Grupo Opará/Mutum utilizam predominantemente técnicas de metodologias qualitativas, não por desconsiderar a importância dos dados quantitativos, mas pelo interesse em compreender a densidade e complexidade do processo junto aos sujeitos que realizam a migração, enquanto um fenômeno multifacetado. Neste sentido, buscamos realizar uma análise interdisciplinar, com aporte da sociologia, geografia humana e da antropologia, por meio do conhecimento oral e das narrativas, onde as informações são conduzidas através da memória das pessoas do lugar, com enfoque no vivido.

Guiadas pelas análises de Sayad (1998) e com base nos dados colhidos em trabalhos de campo, consideramos e nos referimos à migração como mais do que o movimento de sair e chegar, mas como um processo social complexo, de ir e vir, de percursos, presença e ausência, para além do deslocamento geográfico físico, ou seja, um fato social total. Nesse sentido, analisamos também a sociedade, abarcando sua dimensão diacrônica (perspectiva histórica) e sua extensão sincrônica (estruturas e funcionamentos presentes da sociedade) (Sayad 1998: 16).

Dessa forma, realizamos estudo bibliográfico e trabalhos de campo, avaliando sua importância como mais do que um ato puramente científico, mas como a vivência na relação mais diversa, que produz uma nova visão do pesquisador, uma interpretação do sujeito enquanto agente, para que a pesquisa seja não apenas um trabalho sobre eles, mas também com eles.

As reflexões de Brandão (2007) sobre o trabalho de campo inspirou-nos a percepção deste ato como vivência, relação de intensa subjetividade, que requer ligação de confiabilidade entre o pesquisador e os sujeitos da pesquisa. $\mathrm{O}$ autor nos alerta para as inúmeras dimensões que podemos encontrar em campo e como é necessária extrema atenção, desde a forma de inserção às maneiras de conduzir as entrevistas.

As técnicas de pesquisa, incorporadas ao método etnográfico, foram fundamentais para manter viva e registrada as informações obtidas ao longo do trabalho, dentre elas, observação participante, entrevistas livres e o uso do diário de campo. Cabe salientar que não tivemos pretensão de realizar uma etnografia, pois entendemos que esta não se aplicaria ao tempo disponível para a realização das pesquisas. Para Magnani (2012: 17), este método não se confunde nem se reduz a uma técnica, pode-se usar ou servir-se de várias, conforme as circunstâncias de cada pesquisa.

A etnografia nos foi inspiração, pois entendemos, conforme Geertz (1989), que é no estar $l a^{5}$ que o pesquisador formulará suas interpretações, ressaltando que para o autor esta é de segunda e terceira mão, pois apenas o nativo faz a interpretação de primeira mão da sua cultura. Nesse sentido, 
procuramos estar presente na realidade de nossos sujeitos de pesquisa e utilizamos da observação participante e do registro no diário de campo.

Somadas as técnicas etnográficas, realizamos também entrevistas semiestruturadas, buscando compreender com maior profundidade a história de vida dos migrantes. Esse processo ocorreu em junção com estudos e leituras de bibliografias, documentos e análises de alguns dados secundários, como por exemplo, censos do Instituto Brasileiro de Geografia e Estatística (IBGE). Além disso, utilizamos gravadores, máquina fotográfica e roteiros de entrevistas, a fim de organizar um importante acervo para o momento da escrita e reflexão sobre os dados. A escuta dos homens e das mulheres que migram, dos membros da família que ficam, o registro das imagens do cotidiano migratório, auxiliaram na compreensão do fenômeno através daqueles que vivem a migração.

Nossa metodologia é baseada no estar lá, em vivenciar junto com os migrantes o ato de sair do lugar, de observar e ouvir os relatos dos que ficam a esperar o retorno daqueles que fazem as viagens para as "fazendas" ou "firmas", como denominam os destinos dos trabalhos nas lavouras de café, cana de açúcar e capim braquiária, onde se deslocam em determinadas épocas do ano; bem como as idas para trabalhos nas cidades e capitais como São Paulo e Belo Horizonte.

Compreendemos, junto com Woortmann (1995), que as famílias são dotadas de um valor cultural que estrutura as ações e as relações sociais dos indivíduos. Nesse sentido, consideramos enquanto família, aqueles que vivem na mesma casa e/ou aqueles com quem estabelecem relações de afetividade e parentesco. Estudamos, nos grupos familiares pesquisados, como as ações de partir e de permanecer são mediadas pela saudade e configuram-se enquanto uma condição necessária para a reprodução social das mesmas.

Os relatos descrevem a vida como suspensa, e fazem a distinção entre o mundo da vida e o mundo do trabalho. A vida é o lugar de origem, onde ficam os entes queridos a esperar o retorno das migrações, o mundo do trabalho é as fazendas, as firmas, os alojamentos, as dez horas, doze horas de trabalho árduo em um único dia (PAULA 2009).

\section{BREVES DEFINIÇÕES DAS MIGRAÇÕES}

Migração é uma denominação utilizada para referir-se a, sobretudo, mobilidade ou deslocamento espacial da população. Indivíduos movimentando-se dentro de um espaço geográfico, seja de forma temporária ou definitiva é, de maneira geral, o que configura um deslocamento que pode se tornar o início do processo migratório. Diversos são os fatores que desencadeiam esse movimento, e engloba um vasto campo de aspectos históricos e sociais que conferem complexidade ao tema. Para Salim (1992), há a necessidade de compreender essas 
complexidades, incorporando outras possibilidades, como: as migrações temporárias e a migração de retorno às regiões ou cidades de origem. $\mathrm{O}$ autor ressalta, que apesar das migrações temporárias não serem apontadas nas estatísticas dos censos, são importantes para a compreensão do fenômeno e podem ser ainda mais expressivas a nível numérico ou socioeconômico.

Neste sentido, para estudarmos o processo migratório vivido pelos trabalhadores e trabalhadoras Norte Mineiros, a migração é entendida como um fato social total (SAYAD 1998), um processo social complexo e historicamente condicionado, que se faz presente na vida das famílias como uma estratégia de reprodução social, modificando o indivíduo que migra e aqueles que permanecem.

Para Martins (1988), quando o migrante retorna já não é o mesmo, vive uma ruptura de modos e costumes, modifica o que é, e também sua maneira de ver o mundo. Há também uma modificação na vida dos que ficam e que passam a conviver com a ausência dos seus membros, criando estratégias de permanência no lugar de origem. Já os migrantes temporários, para Martins (1988), estão inseridos em um universo social em que, mais do que estar em trânsito de um lugar a outro, vivem uma transição de um tempo a outro, vivem em espaços geográficos diferentes e temporalidades dilaceradas pelas contradições sociais.

Analisando o processo de expropriação/exploração gerados pelo desenvolvimento do capitalismo no Brasil, que suscitou a expulsão dos pequenos lavradores de suas terras, o autor chama a atenção não só para o processo de expropriação em si, mas também a situação de exploração da classe trabalhadora, seus salários e contratos de trabalho irregulares. Nesse contexto, a permanência das mulheres e filhos trabalhando na unidade de produção, e a exploração do chefe de família na migração, tornou-se uma possibilidade de reprodução social do núcleo familiar.

Damiani (2011) afirma que no Brasil, a migração temporária interna é decorrente do processo de reprodução da grande propriedade, onde as grandes empresas capitalistas, nacionais e internacionais, incentivadas pelo Estado, substituíram os grandes latifúndios. Nesse processo, o Estado financiou os interesses das grandes corporações agropecuárias, a partir de mecanismos como a assistência técnica gratuita, subsídios nos empréstimos bancários, entre outros.

A região Norte Mineira viveu nas décadas de 60,70 e 80 do século XX, intensa expulsão de seus habitantes para outras regiões do Brasil, auxiliando na urbanização e industrialização do país. A migração tornou-se parte do cotidiano das famílias de pequenos produtores e camponeses que tiveram suas terras expropriadas, principalmente a partir da modernização do campo e das políticas públicas que reproduziram o discurso e a busca por um desenvolvimento vinculado à ideia de progresso meramente econômico. Observamos que migrar é uma estratégia, ou mesmo uma 
condição de reprodução social das famílias, uma forma de resistência e possibilidade de permanecer, visto que muitos migram para que as famílias continuem na região.

\section{PORTEIRINHA: DO OURO BRANCO AS MIGRAÇÕES TEMPORÁRIAS}

O universo de estudo desta pesquisa está localizado na mesorregião Norte de Minas, formada por 89 municípios agrupados em 7 microrregiões: Bocaiúva, Grão Mogol, Janaúba, Januária, Montes Claros, Pirapora e Salinas. Porteirinha é um município da Microrregião de Janaúba (MAPA 1), limita-se com os municípios de Mato Verde, Pai Pedro, Riacho dos Machados, Rio Pardo de Minas, Serranópolis de Minas, Janaúba e Nova Porteirinha e fica a $582 \mathrm{~km}$ da capital mineira e a $165 \mathrm{~km}$ da cidade de Montes Claros. Após a emancipação de Riacho dos Machados (1962), Serranópolis de Minas e Pai Pedro (1995), o município passou a abarcar seis distritos: Bom Jesus, Mocambinho, Paciência, Mulungu, Serra Branca e Tocandira, tendo no ano de 2018, uma população total estimada de 37.950 pessoas, segundo os dados do IBGE.

\section{MAPA 1: Município de Porteirinha na Microrregião de Janaúba}

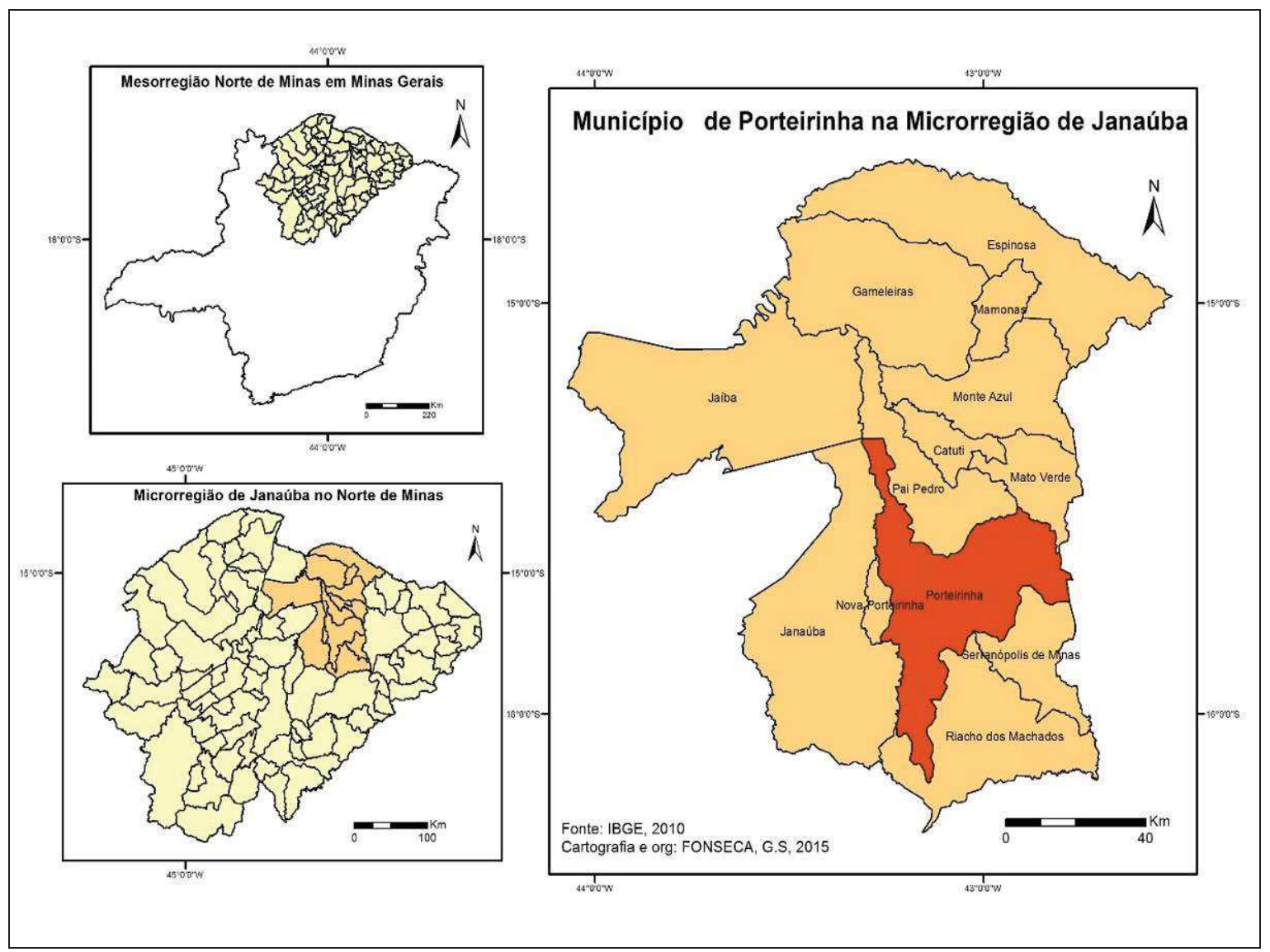

Fonte: IBGE (2010). Cartografia e Org.: Gildette Soares Fonseca (2015) 
Porteirinha, como a maioria dos municípios da região, originou-se a partir de uma pousada de viajantes à margem do rio Gorutuba e seus afluentes, rio Mosquito e rio Serra Branca. O local que originou a povoação, era apenas um movimentado ponto de pousada para os viajantes que destinavam o Sul do estado e do País, vindos da vasta região do Nordeste brasileiro.

Os prováveis primeiros habitantes foram os tropeiros Severino dos Santos, José Cândido Teixeira, José Antônio da Silva, João Soares, João de Deus, João Pereira e José Miguel, que aqui chegaram nos primórdios do século XVIII. Vieram à cata de ouro. Cessada a febre do metal, tornaram-se senhores de grandes extensões de terras e escravocratas poderosos. Dedicavam-se à lavoura, empregando os escravos em suas propriedades. (Oliveira 2008: 17-18)

Na história de Porteirinha temos o período da produção de algodão como momento constituidor da história do município. A produção do algodão foi intensa, especialmente nas décadas de 1960 a 1980, devido à capacidade do algodão de adaptar-se ao clima semiárido e aos incentivos a linhas de créditos rurais. A monocultura de algodão foi parte da lógica das políticas desenvolvimentistas propostas pelo Estado para a região, sendo incorporada aos pacotes que visaram fortalecer os reflorestamentos, agroindústrias, industrialização e a pecuária de corte.

Além do fator econômico, a monocultura interferiu totalmente nas dinâmicas locais, no espaço, na cultura e portanto, na vida das pessoas. Porteirinha foi chamada de Capital Mineira do Algodão e até hoje é comum ouvir moradores chamando esse produto de ouro branco, trazendo em suas memórias, as esperanças de tempos de fartura, "desenvolvimento" e melhoria de vida.

Nilton César de Oliveira, agricultor familiar e presidente do Sindicato dos Trabalhadores Rurais de Porteirinha em 2016, relembra que sua decisão de pausar os estudos ocorreu em função dos fascínios que o algodão trouxera. Havia o desejo de comprar uma bicicleta, que naquele momento poderia se concretizar, porém, devido o trabalho cansativo na plantação, o tempo para a escola não "sobrava": “...quando eu via um primo ou uma amiga andando em uma bicicleta nova eu ficava encantado e com o maior sonho de comprar uma. Eu não tinha dinheiro, achei por bem eu desistir da escola e ir plantar algodão para poder comprar uma bicicleta nova" (Depoimento concedido em trabalho de campo das autoras em 2016). No período do auge do algodão direta ou indiretamente toda a população do município estava envolvida com a produção. Esse envolvimento aconteceu por muitas vezes de formas bem distintas, mas foi um momento narrado pelos moradores de Porteirinha, como de crescimento e desenvolvimento para o município.

Naquele período, esta cultura foi tida como muito importante para o Norte de Minas, refletindo no processo de grande geração de emprego e boas condições financeiras, além de ser um 
possível estímulo para a permanência das pessoas nos seus lugares de origem, ou seja, acarretando na diminuição das migrações do campo para a cidade.

\begin{abstract}
De acordo com a empresa de Pesquisa Agropecuária de Minas Gerais - EPAMIG, no processo de produção do algodão no Norte de Minas estão envolvidas 12.000 famílias diretas, predominantemente pequenos produtores. A mão-de-obra utilizada na condução da cultura (4 dias homens/ano) caracteriza a atividade como a maior de trabalhadores rurais na região, evitando a migração do homem do campo para os centros urbanos, gerando 23.000 novos empregos diretos, por ano. Trabalhando nos setores ligados à atividade (indústria, têxtil, beneficiamento e comércio) estima-se o envolvimento de mais ou menos 40.000 pessoas. (ANTUNES FILHO 2000: 36-37)
\end{abstract}

Após o ápice da produção, a partir de 1980, a monocultura entra em fase de declínio, o que impactou de diversas formas os moradores. Na busca de compreender a crise, muitas causas são citadas pelos entrevistados, dentre elas, o fato de ser uma monocultura com lógica diferente da forma tradicional, que produzia em conjunto, uma diversidade de espécies. Houveram também, relações conflituosas com os empresários e políticos, que compravam o algodão para vender para as usinas, ocasionando em dívidas por adiantamentos e constatações de que foram os únicos que realmente lucraram com o algodão. Juntamente, associam o decaimento da produção a fatores relacionados a infestação de uma praga, denominada bicudo.

Das "riquezas" extraídas através do ouro branco decorreram-se crises que revelaram uma série de pontos negativos. O fato da produção do algodão passar a ser uma monocultura interferiu bruscamente na forma de produção tradicional. A agricultura familiar, através de sua maneira diferenciada de trabalhar a terra, foi interrompida, pois existia uma relação de territorialidade, analisada por Little (2002: 3) como o: “... esforço coletivo de um grupo social para ocupar, usar, controlar e se identificar com uma parcela específica de seu ambiente biofísico, convertendo-a assim em seu "território". A monocultura impossibilita esse sentimento, a identificação com o seu meio, além de ter resultado em grandes impactos sobre o ambiente, atacando as sementes crioulas ${ }^{6}$, as diversidades de espécies, a cultura e os modos de vida locais.

Os moradores narram que, para plantar o algodão, foi preciso desmatar através de maquinário pesado. Acabaram com o capoeirão, derrubaram os umbuzeiros, começaram a utilizar agrotóxicos e as antigas baixadas de terra, que eram boas para plantar arroz, se transformaram em bancos de areia que desciam dos lugares mais altos e passaram a ir direto para os rios. A monocultura veio como um pacote do governo federal e através dos incentivos de linhas de crédito rural, os agricultores familiares de Porteirinha aderiram à racionalidade de produção em larga escala. Identificamos dois movimentos migratórios consequentes desse período: a migração permanente, enquanto consequência do endividamento bancário das famílias e a perda dos territórios, e a migração temporária para as colheitas sazonais em outras regiões do Brasil. 
Deste modo, compreendemos que a monocultura de algodão é uma das causas das migrações do município. Porteirinha foi atingida por políticas e incentivos que carregaram consigo o discurso do desenvolvimento e da modernidade, mas isto de maneira excludente, assim como em outros municípios Norte Mineiros.

O censo do IBGE do ano de 2010 aponta, a partir da variável data fixa, que se refere ao lugar de residência do sujeito cinco anos antes da data do censo do IBGE, que em 31/07/2005, 1 712 pessoas não residiam em Porteirinha-MG. Esses são considerados, pelo IBGE, os migrantes do município. Consideramos esses dados censitários representativos, mas não delimitam as migrações temporárias nos municípios, pois não indicam os indivíduos que saem do seu lugar de origem temporariamente, que partem em busca de uma situação econômica diferente daquela que encontram em seu município; trabalham por determinado período e voltam para o seu lugar de origem.

A dinâmica populacional local também reforça esse processo de expulsão do rural, como demonstrado em comparação na tabela (Tabela 1). De 1970 a 2000, a população rural de Porteirinha era maior que a urbana, porém, a população rural de 1970 até o último censo (2010) veio decrescendo, enquanto a população urbana cresceu. O período de maior declínio da população rural se encontra justamente após o auge da monocultura do algodão (1980-1991). A população total apresentou tanto acréscimos como decréscimos. E em 2010 temos a menor diferença entre rural e urbano, apenas 1.049 moradores.

Tabela 1 - População rural, urbana e total de Porteirinha-MG. 1970, 1980, 1991, 2000 e 2010

\begin{tabular}{lrrr}
\hline CENSO & POPULAÇÃO URBANA & POPULAÇÃO RURAL & POPULAÇÃO TOTAL \\
\hline 1970 & 5.004 & 36.737 & 41.741 \\
1980 & 11.472 & 34.580 & 46.052 \\
1991 & 15.410 & 22.351 & 37.761 \\
2000 & 18.140 & 19.630 & 37.770 \\
2010 & 19.338 & 18.289 & 37.627 \\
\hline
\end{tabular}

Fonte: IBGE (2017). Org.: Maria Cecília Cordeiro Pires (2017)

Durante a pesquisa, através dos trabalhos de campo, fomos conhecendo um pouco mais sobre a dinâmica do processo migratório no município, das migrações para as colheitas e para as cidades, do ir e vir, do chegar e logo partir. Um processo complexo, que mesmo estimulado pelo declínio da monocultura algodoeira, é permeado de diversas motivações, histórias e contextos. Nesse sentido, apresentamos a migração a partir das perspectivas dos que partem e dos que ficam. 


\section{RESULTADOS: SAINDO PARA AS COLHEITAS E PARA AS CIDADES: A MIGRAÇÃO PELA PERSPECTIVA DOS QUE PARTEM}

No contexto das migrações temporárias, os trabalhos de campo foram marcadas pelo calendário fluído das idas e vindas dos migrantes. Algumas conversas traziam um sentimento de expectativa, onde já na véspera da saída para as colheitas, os planos eram feitos: "esse ano mesmo eu queria ver, se Deus abençoar e eu ganhar um dinheirinho a mais para eu vender essa moto e comprar uma melhor" (Depoimento de Gercílio Rodrigues dos Santos, 62 anos, concedido em trabalho de campo das autoras em 2016).

Em outros momentos haviam acabado de retornar, mas nas falas indicavam a continuidade, "enquanto eu tiver vida e saúde eu tô mexendo" (Depoimento de Gilberto Pires Silveira, 63 anos, concedido em trabalho de campo das autoras em 2016). Ressaltam os sonhos que realizaram com as migrações, sonhos esses que representam que não existe só a fome do alimento, com o tempo, novas "exigências" vão sendo feitas, e por isso as marcas da migração vão para além daquelas percebidas nas mãos calejadas, na pele queimada, na feição envelhecida. As marcas também estão pela casa, nas paredes coloridas, na televisão de plasma, nos eletrodomésticos e na tão sonhada motocicleta. As saídas para as migrações expressam sonhos de consumo, sonhos de quem migra, sonhos de quem fica. O recurso financeiro que é fruto do trabalho realizado geralmente por apenas um membro da família, que é quem migra, é partilhado por todos os demais membros. A ida é individual, mas o retorno é coletivo.

Foto 1: Migrantes temporários em suas residências- Porteirinha-MG
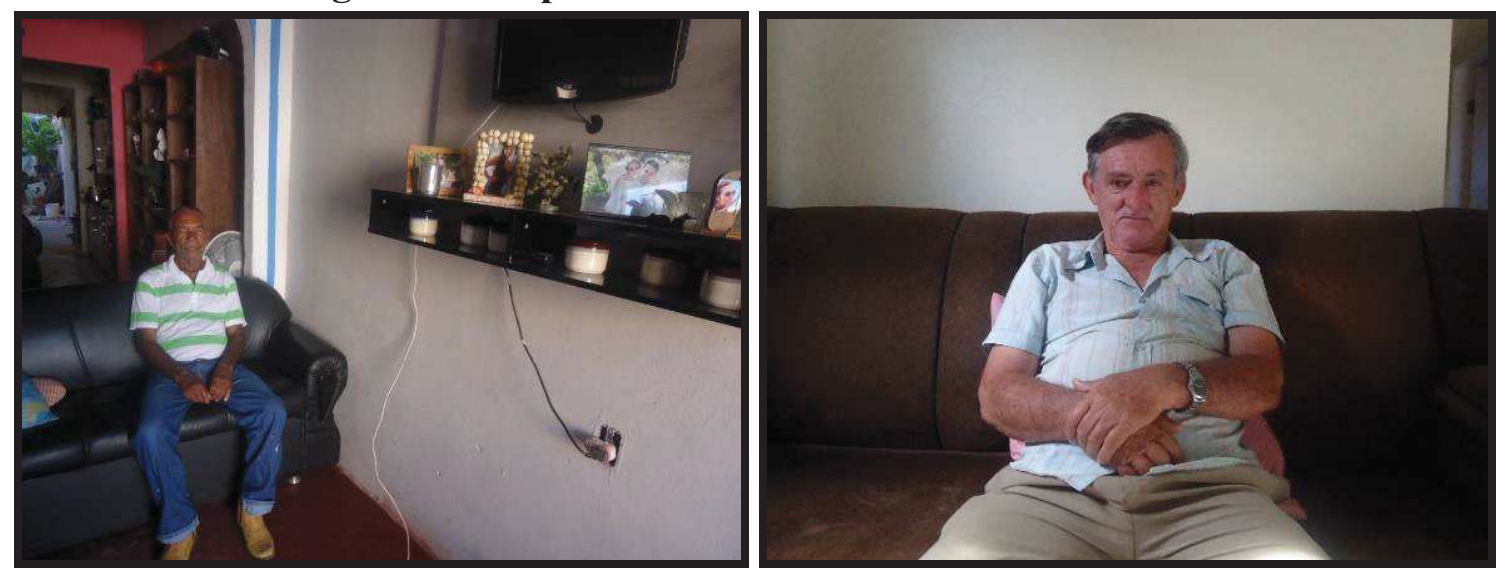

Fonte: Maria Cecília Cordeiro Pires (2016)

Os fluxos mais intensos mencionados pelos moradores são os destinados para o corte de cana e a colheita do café. Ocorrem também as primeiras idas, no final do século XX, para o corte do capim braquiária, o plantio e colheita da laranja, entre outras safras. As turmas, modo como se 
referem ao deslocamento para o trabalho temporário realizado em grupos, eram organizadas pelos gatos, como ficaram conhecidos os homens responsáveis por recrutar as pessoas para os trabalhos nas fazendas, onde inclusive relataram condições degradantes.

O povo não acha serviço na roça e nem na zona urbana, aí sai para fora, para longe, para trabalhar, para ganhar um dinheirinho, plantar café, cana. Aí sai para fora, para longe, traz um dinheirinho pra cidade, pra mexer com a família, pra criar a família. (Depoimento de Gilberto Pires Silveira, 63 anos, concedido em trabalho de campo das autoras em 2016).

Nós já precisamos fretar ônibus aqui, pra ir buscar gente que estava com trabalho escravo em fazenda e não tinha condição de vir embora e o povo não mandava embora. Ligaram pra gente, pedindo pelo amor de Deus! A gente acionou o Ministério do Trabalho lá, foram na fazenda e realmente estavam. Então o sindicato fretou um ônibus pra trazer de volta. (Depoimento Elton Mendes Barbosa, membro do STRP e da ASA Minas, concedido em trabalho de campo das autoras em 2016)

As migrações deslocam não apenas o migrante de um lugar para outro, deslocam suas vivências, interferem na vida familiar. É um enfrentamento a lugares não conhecidos, com modos de trabalho e relacionamentos distintos do que os de costume. Saem com a visão de trabalho enquanto valor, mas defrontam com o trabalho como mercadoria, que os distanciam da sua territorialidade.

Percebemos na pesquisa, que o calendário da migração temporária tem relação com o calendário rural, marcado na região pelo tempo das secas e o tempo das águas. O Sr. Gercílio Rodrigues de 62 anos, relata que vive os dois tempos: o trabalho na zona rural do município e o trabalho nas migrações temporárias. Narra que o período que vai para a colheita do café no Sul de Minas é o tempo da seca em Porteirinha, o que dificulta o trabalho na terra: "aqui não passa o clima da seca não, você saindo fora três meses, aqui fica mais perto de começar as águas".

Com base nos depoimentos dos migrantes, elaboramos o seguinte calendário, que demonstra como as vidas desses sujeitos são pensadas em função da migração, bem como a migração é planejada através do dia a dia:

Quadro 1 - Calendário das Migrações Temporárias dos Trabalhadores de Porteirinha - MG

\begin{tabular}{|l|c|c|c|}
\hline Janeiro & Fevereiro Março & Abril \\
\hline \multicolumn{3}{|c|}{ Entre Águas e Secas } \\
Os migrantes temporários neste período permanecem em Porteirinha. Na cidade se \\
ocupam de bicos (prestação de serviços), na zona rural retornam ao trabalho em suas \\
terras ou como arrendatários. O Programa Bolsa Família é complemento para a renda \\
nesse período. \\
\hline Maio & Junho & Julho & Agosto \\
\hline
\end{tabular}




\section{Período da Seca}

Época das plantações de algodão, café, cana e preparação de pastos.

Em maio os trabalhadores começam a sair para o Mato Grosso e Pará e em junho para o Sul de Minas. O Programa Bolsa Família é um complemento para os familiares que ficam no município.

\begin{tabular}{|c|c|c|c|}
\hline Setembro & Outubro & Novembro & Dezembro \\
\hline \multicolumn{3}{|c|}{ Período das Águas } \\
Setembro é marcado pelo retorno dos migrantes do Sul de Minas, entre outubro e \\
novembro os de Mato Grosso e dezembro os do Pará. Essas datas variam dependendo da \\
safra, chuvas, etc. Depois que retornam, o ciclo novamente se repete.
\end{tabular}

Org: Maria Cecília Cordeiro Pires (2016)

A contradição parece estar em tudo. Ao migrar vão para um lugar que não é o seu, quase tudo causa estranhamento, desde o clima até o tipo de trabalho. Até mesmo para os agricultores que vão para áreas agrícolas, pois precisam lidar com uma forma diferente de trabalhar com a terra, afastados dos saberes tradicionais.

Nas entrevistas e conversas informais, os migrantes evidenciam as diversas dimensões do processo migratório. Migram para melhorar de vida, para resistir, para permanecer. Iniciam e continuam a viagem por conta dos laços de reciprocidade que os ligam a outros migrantes, sendo as relações de parentesco e afinidades proporcionadoras de uma facilidade para a entrada de novos migrantes, como também, confiança para o início dessa empreitada. Esse movimento é conceituado por Woortmann (2009: 222) como rede social de apoio, onde os primeiros a migrar para garantir o retorno precisam conhecer o destino e entender como conviver no novo espaço social e assim facilitam e divulgam para que outros possam migrar.

Essa rede, que é formada nas migrações temporárias, também é presente nas migrações permanentes para outras cidades. Existe uma rede familiar e de amizade, aonde um conhecido ou parente vai incorporando ou abrigando aqueles que chegam. As experiências de outros também serviram para influenciar a vontade de ir, ou de se aventurar, como disse Maria de Lourdes, de 53 anos, que atualmente trabalha como doméstica e mora com a filha mais nova em Porteirinha. Dos seus seis filhos, todos já migraram, sendo que a mais nova a acompanhou em uma ida para o Paraná ainda criança. Mesmo apontando as dificuldades de adaptação na cidade grande, a maioria migrou mais de uma vez, tendo como destino a região metropolitana de Belo Horizonte e posteriormente uma cidade do estado do Paraná.

Durante o trabalho de campo, observamos que nas idas para a migração nas colheitas, são recorrentes as histórias dos homens que migram e das mulheres que ficam para manutenção do vínculo com o lugar de origem; em contrapartida, nas migrações para as cidades, os relatos demonstram uma incidência de mulheres para o trabalho doméstico e prestação de serviços no 
comercio local. Maria de Lourdes é uma das mulheres que realizaram a migração para a cidade grande. Migrou para Belo Horizonte, capital de Minas Gerais e depois migrou para o Paraná. Após sua experiência, duas de suas filhas também realizaram a migração.

Ludmila, filha de Maria de Lourdes, atualmente trabalha em um supermercado na cidade de Porteirinha. Ela tem 25 anos, mora com sua filha e o companheiro no Bairro Mato Verde, na margem da BR MG-122, que liga Porteirinha ao município de Mato Verde. A experiência de migração de Ludmila foi para um trabalho em Belo Horizonte, conseguiu uma passagem gratuita para a capital através da Prefeitura Municipal de Porteirinha, e comunicou aos seus familiares poucos dias antes da viagem. Morou neste período com parentes em um bairro periférico de Contagem (região Metropolitana). A princípio, realizou serviços como manicure, e após um mês conseguiu trabalho em um supermercado de Belo Horizonte, passando a viver o deslocamento pendular. A decisão do seu retorno foi em função da convivência na casa que estava, contudo, atualmente Ludmila ainda expõe sua vontade de sair de Porteirinha.

O que podemos destacar, entre tantas histórias que nos foram compartilhadas naquela noite, é como a migração está presente em sua vida, pois sua mãe e irmãos também já saíram para trabalhar em outros municípios. Ludmila nos disse que conhece várias pessoas que foram para Belo Horizonte, inclusive apontou o distrito de Angicos como lugar que saem muitos porteirinhenses, trabalhando geralmente em uma caixotaria, o que foi apontado também em outras entrevistas.

Em um sábado atípico em Porteirinha, de tempo fresco e chuvoso, conseguimos conhecer as histórias de Hosano, Maria de Lourdes, Dalcy e Rodrigo. Hosano tem 46 anos, três filhos e é solteiro. Atualmente é serralheiro autônomo, mora sozinho numa casa construída no mesmo lote, junto à casa de sua mãe. Maria de Lourdes tem 53 anos, hoje trabalha como doméstica e mora com a filha mais nova, tem seis filhos, todos já migraram. Dalcy tem 40 anos, atualmente trabalha como gari, tem quatro filhos, alguns deles e seus netos moram com ela. Rodrigo tem 33 anos, trabalha numa serralheiria, mora com sua esposa e três filhos na casa da mãe.

No acontecer do trabalho de campo, quatro dessas histórias se cruzaram. Maria de Lourdes é a Mãe de Ludmilla, que dentre outros destinos teve a migração para Belo Horizonte para trabalhar como doméstica. O contato para esse emprego foi através de Hosano, que foi três vezes para a capital mineira e uma vez para São Paulo, trabalhar com serralheria. Dalcy e Maria de Lourdes são vizinhas e moram num bairro da periferia do município, as duas migraram na mesma época para Belo Horizonte, porém, Dalcy foi cuidadora de uma idosa, ela teve outra experiência mais longa em São Paulo, antes dos filhos, e partilhou conosco uma história afetada pela violência, e de grandes dificuldades. 


\section{Fotos 2: Porteirinhenses que Migram para Capitais e Regiões Metropolitanas - Porteirinha-} MG
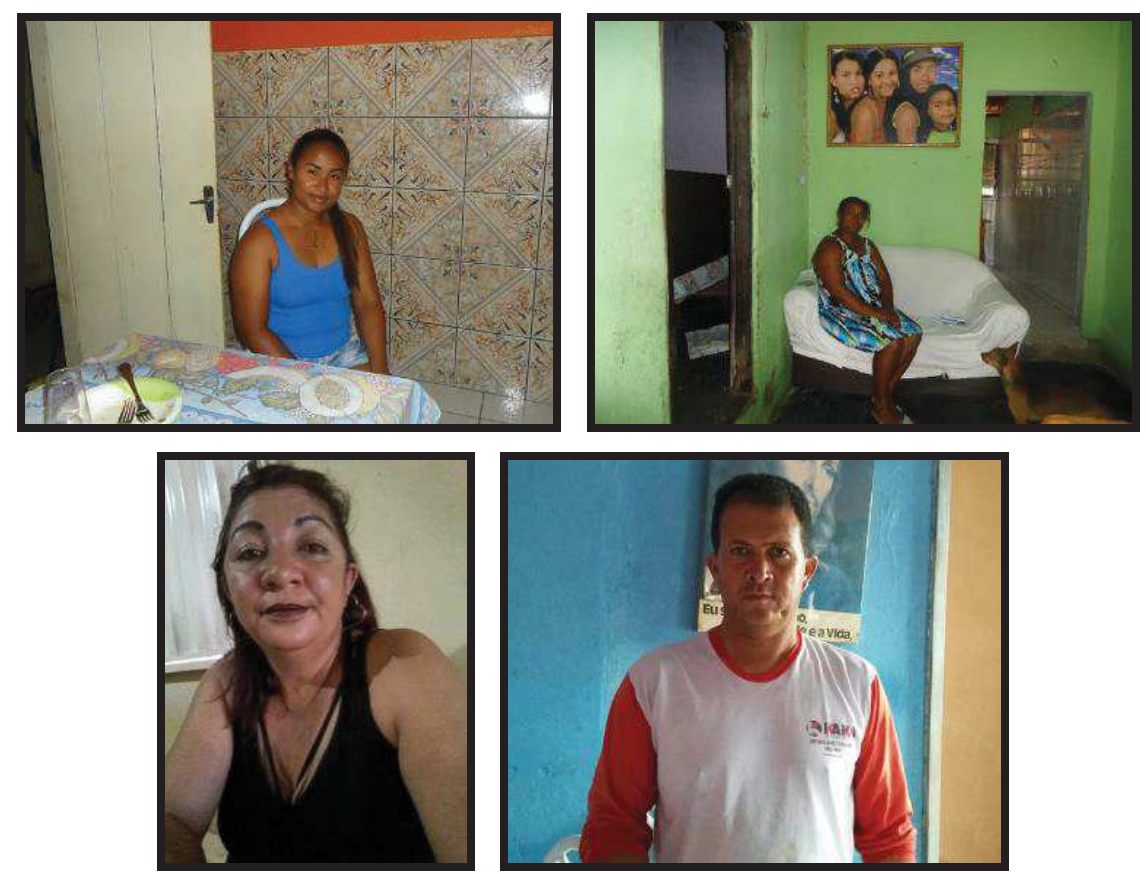

Fonte: Maria Cecília Cordeiro Pires (2018)

Entrevistamos Rodrigo, que com 21 anos migrou pela primeira vez junto de seu irmão. O destino foi São Paulo, na região metropolitana. Seu sonho e objetivo da migração era adquirir recursos financeiros para a compra de um automóvel, mas a realidade que enfrentou foi diferente da idealizada. Não conseguiu colocação e teve que ser acolhido por parentes e conterrâneos que moravam na cidade. Na cidade grande constituiu família e entre pequenos trabalhos e "bicos" permaneceu por dez anos. Agora, aos 35 anos, vive em Porteirinha, casado e com três filhos. Retornou há três anos, mas não descarta a possibilidade de uma nova migração. 


\section{Foto 3: Dia do casamento de Rodrigo - São Paulo-SP}

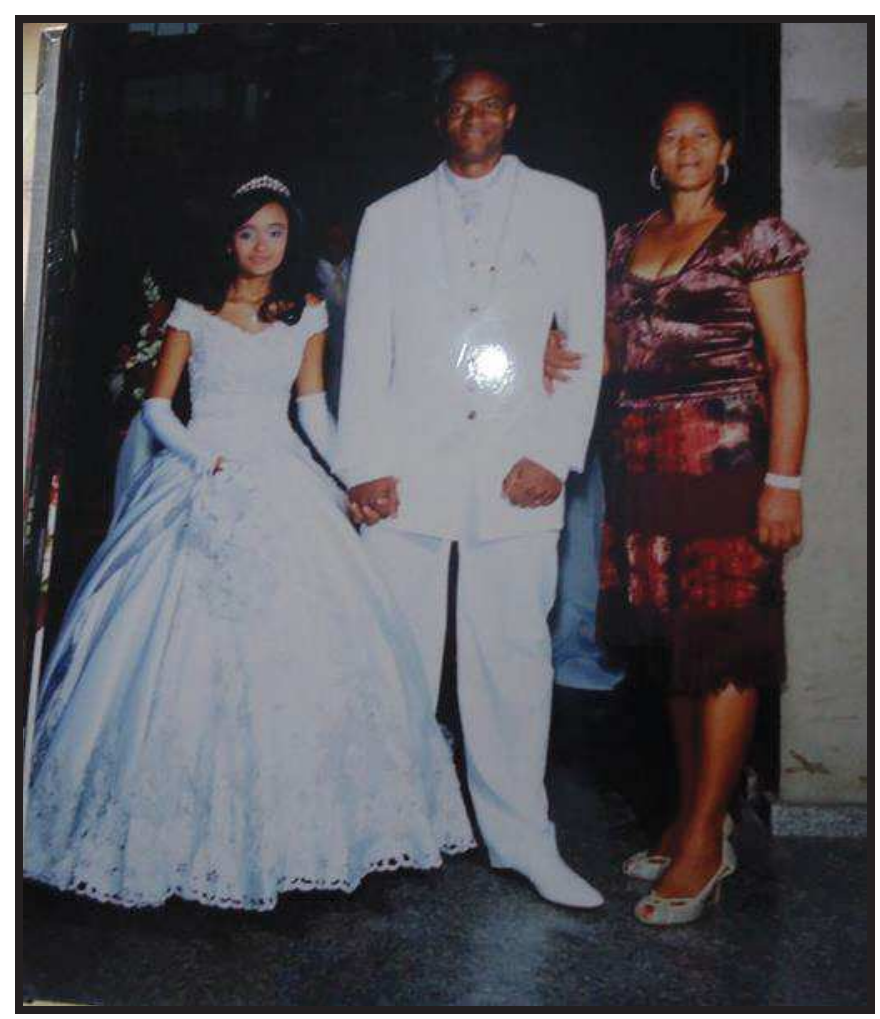

Fonte: Rodrigo - Acervo pessoal (2018)

As narrativas são histórias de lutas, trabalho, espera, esperança, idas, retornos, fé, sonhos. A maioria morou em bairros periféricos, ou no lugar de trabalho, alojamentos ou barracos divididos com muitos outros sujeitos de origens diferentes, mas em comum tiveram os sonhos, e dentre eles, o de retornar. O retorno está presente em todas as narrativas do processo migratório. A alternativa dos porteirinhenses foi sair à procura do "algodão" do outro lugar, do ouro branco! Algodão grafado entre aspas, pois percebemos que essa é uma busca simbólica, a procura de um meio que forneça trabalho e renda como tinham outrora em Porteirinha. Desse modo, diversos destinos e formas de trabalho foram percorridos. Desde as colheitas no Sul de Minas e interior de São Paulo, Mato Grosso e Pará, até os trabalhos no perímetro urbano de Belo Horizonte e São Paulo (Foto 4). 


\section{Foto 4: Alguns Destinos e Trabalhos de Migrantes Porteirinhenses - Mato Grosso, São Paulo,} Pará
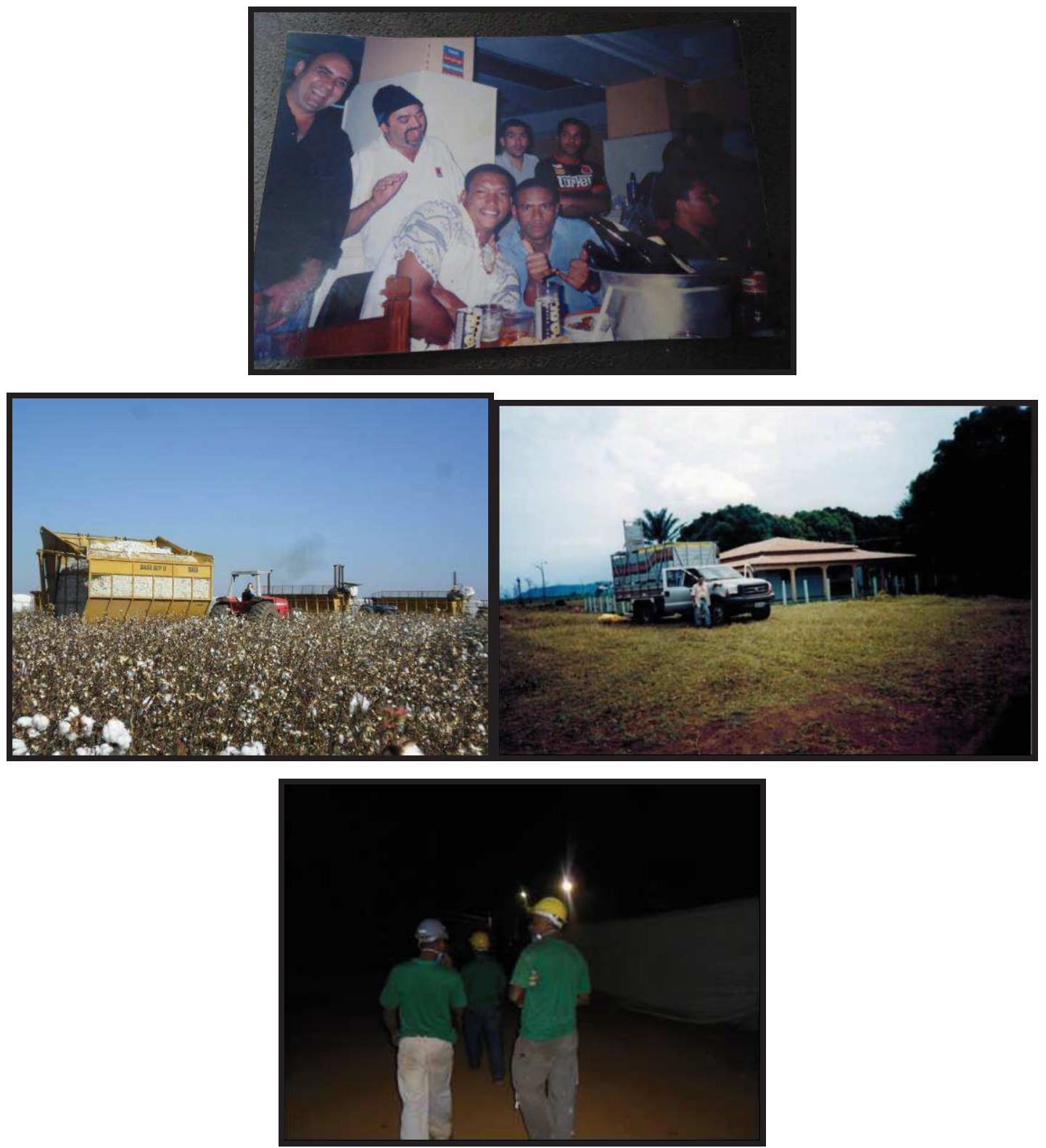

Fonte: Acervos pessoais cedidos nos trabalhos de campo (2016 - 2018)

Como apontado por Sayad (2000), o retorno se torna intrínseco ao processo migratório. O migrante temporário vai para as colheitas já pensando na volta, e mesmo vivendo as chegadas e partidas, procura sempre retornar. Nas migrações longas para as cidades, muitos foram e ficaram, e quando não conseguem retornar buscam o sentido de estar em casa, através da memória. Resgatam os cheiros e sabores do seu lugar e nas "visitas de retorno", são muitas as caixas térmicas com frutos, queijos, doces, que circulam nos bagageiros dos ônibus possibilitando levar um pouco de casa. Mas é preciso salientar que o retorno, quando atingido, também traz muitos sentimentos: a alegria pode vir junto da frustação de não ter atingido os sonhos de antes, o lugar de saudade pode 
parecer diferente, pois a viagem de volta transforma aqueles que partiram e os que ficaram. Uma vida entre trânsito e transição.

\section{ENTRE PARTIDAS E CHEGADAS: A REPRESENTAÇÃO DAS MIGRAÇÕES PARA OS QUE FICAM}

Maria Do Carmo tem 52 anos de idade, é casada com Gersílio, migrante temporário, e mãe de duas filhas. Viveu intensamente a experiência migratória. Mudou-se para o meio rural de Porteirinha junto com seu marido, para trabalharem como arrendatários no terreno de um tio, padrinho de sua filha Gersilene, que tem 29 anos, trabalha como manicure e está cursando Pedagogia.

Foto 5: Maria do Carmo, Gersílio e Gersilene - Porteirinha-MG

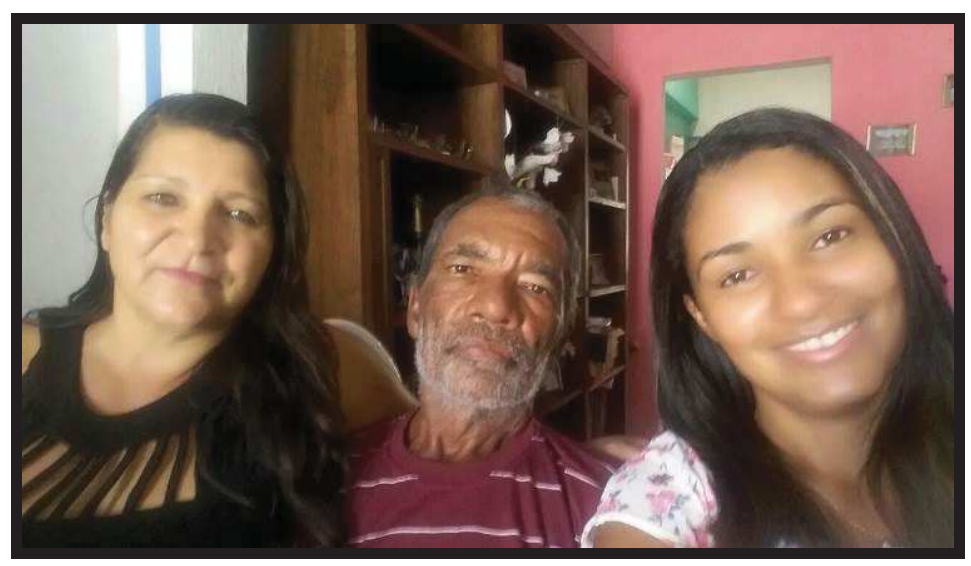

Fonte: Gersilene - Arquivo Pessoal (2017)

A família de Maria do Carmo e Gersilene viveu por 16 anos como arrendatários nas terras do tio/padrinho/compadre. Plantavam, colhiam, lidavam com ração para os bichos e toda a gama de variedades de atividades que a terra possibilita. Dividiam os lucros ao meio com o proprietário. Porém, em um determinado momento, o mesmo resolveu vender a terra e eles tiveram que mudar para a cidade. 


\section{Foto 6: Fachada da casa de Maria do Carmo e Gersílio - Porteirinha-MG}

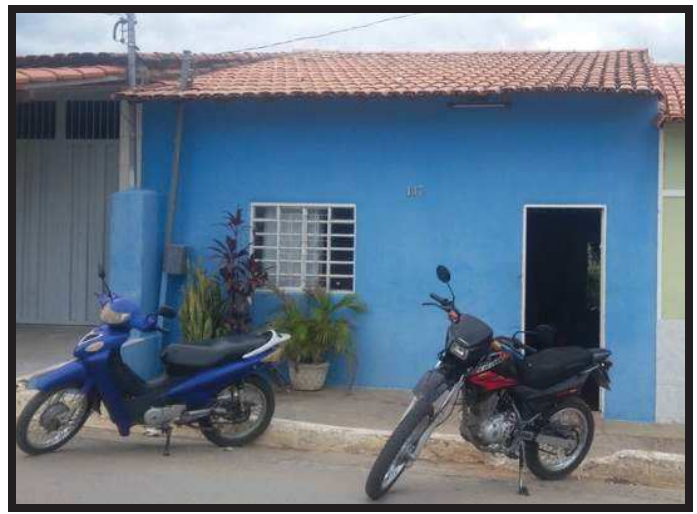

Fonte: Carla Nadinne Souza (2017)

Gersilene relata que a migração temporária de seu pai Gersílio, começou a acontecer depois dos anos 2000, quando se mudaram da roça para a cidade, período muito difícil. Gersílio não possuía estudo nem qualificação profissional, o que dificultou sua inserção no mercado de trabalho. Acostumado às atividades da lida na roça, mesmo depois da mudança para a cidade, não conseguiu emprego. A possibilidade, portanto, veio através das migrações. Quando não está nos trabalhos temporários fora de Porteirinha, presta serviços na zona rural da cidade: "Até hoje trabalha roçando, capinando, fazendo cerca, queimando mato, essas coisas. Ele vai todos os dias, pega a bicicletinha e vai trabalhar lá na Várzea Bonita, pros outros" (Depoimento de Maria do Carmo, 52 anos, concedido em trabalho de campo das autoras em 2017).

A migração de Gersílio trouxe grande impacto nas vidas de Maria do Carmo, Gersilene e da outra filha do casal. O fato de ser o chefe da família, o único homem da casa, trouxe para vida das mulheres um vazio, uma insegurança. Os dias eram permeados pela saudade, pelo sofrimento, pela preocupação. O período da noite é o que relatam como o pior. Mas, aos poucos foram se adaptando e os benefícios trazidos pela migração, de acordo com a família, passaram a compensar a distância, a preocupação, a ausência, a saudade.

No começo foi muito ruim, porque ele nunca tinha saído, são muitos anos de casamento e nunca teve que sair. O primeiro ano vou falar com você, foi muito difícil. Assim, na casa estava faltando alguém. Quando chegava de noite, duas horas da manhã, acordava e não conseguia dormir, porque quando tem um homem na casa, aí a gente fica mais sossegada. E assim, depois que ele saiu, a gente não fica normal de jeito nenhum, mas tinha que ir pra ganhar um dinheirinho a mais que aqui não ganhava. (Depoimento de Maria do Carmo, 52 anos, concedido em trabalho de campo das autoras em 2017)

Fiquei angustiada nos primeiros anos, fiquei preocupada se acontecesse alguma coisa. Ele também não é muito novinho, mais fácil de adoecer, ainda mais longe da família. A gente sente falta, fica com saudade. Meus filhos mesmo choravam, mas foi acostumando, hoje não importam mais. Aprendeu que o avô vai, mas volta. Quando eles eram mais novinhos tinha medo dele ir e não voltar. (Depoimento de Gersilene, 30 anos, concedido em trabalho de campo das autoras em 2017) 
Segundo Maria do Carmo e Gersilene, o Gersílio migra há aproximadamente 15 anos, o destino geralmente é São Gonçalo do Sapucaí, cidade localizada no Sul de Minas Gerais. A migração acontece todos os anos e geralmente com duração de três a quatro meses. No período que está fora, ele envia dinheiro para Maria do Carmo, a fim de assegurar o sustento da família em Porteirinha.

Ele mandava o dinheiro. Uma vez foi até importante, porque eu precisei fazer um exame e custava quinhentos reais e ele estava no café. Aí eu falei assim: "eu tenho que fazer um exame" e ele falou: "faz, eu mando o dinheiro". Se ele tivesse aqui as coisas iam ser mais complicadas, mas ele estava lá trabalhando e depositou o dinheiro, eu tirei e fiz o exame. Foi muito importante! (Depoimento de Maria do Carmo, 52 anos, concedido em trabalho de campo das autoras em 2017)

As entrevistas com Maria do Carmo e Gersilene ocorreram em tempos distintos. Os relatos expressavam a falta que o Gersílio fez, onde o momento considerado por ambas como o mais difícil, foi o nascimento do segundo filho de Gersilene. Dois meses antes do nascimento, Gersilene e seu marido se separaram, o que trouxe um desgaste para toda família. Maria do Carmo desdobrouse para cuidar de Gersilene, seu filho recém-nascido e sua filha mais velha.

Quando a minha menina ganhou menino, ele não estava aqui. Minha mãe tava morando lá no Gerais. Então assim, eu fui como dizem os outros: o marido, a mãe, tudo. (Depoimento de Maria do Carmo, 52 anos, concedido em trabalho de campo das autoras em 2017)

O nascimento do meu filho foi um período bem complicado que eu e minha mãe tivemos que passar. Eu me separei do meu marido dois meses antes de ganhar ele. Aí assim, foi muito dolorido... Sem marido, sem pai, minha mãe teve que pegar assim, tudo. (Depoimento de Gersilene, 30 anos, concedido em trabalho de campo das autoras em 2017)

Maria do Carmo afirma que seu marido gosta de trabalhar fora, porque criou laços de amizade com outros porteirinhenses que vão para a mesma fazenda. Falou-nos um pouco sobre o que o Gersílio conta sobre o alojamento. A casa é considerada boa, por ser de laje e possuir um chuveiro quente. A única ressalva feita por Maria do Carmo e Gersilene, é quanto à alimentação, segundo as duas, Gersílio não gosta da comida, por ser feita por outro homem.

A alimentação tem hora que ele fala que não é muito boa. Quem cozinha é homem e aqui em casa tem a comidinha da mulher, lógico que a comidinha aqui é mais gostosa. Quando volta, eu acho que ele emagrece lá uns cinco quilos, só chega o cambito. O trabalho lá é muito pesado! Nossa! Eu admiro ele, com sessenta e dois anos e com a força de vontade que ele tem! (Depoimento de Maria do Carmo, 52 anos, concedido em trabalho de campo das autoras em 2017)

Maria do Carmo faz um paralelo entre o que a migração trouxe de positivo e negativo para a família. A partir dela a família teve condições para sobreviver, destacando a compra da motocicleta do casal, motivo de orgulho: “(...) compramos uma moto. Já é alguma coisa, porque se 
ele tivesse aqui nós não teríamos uma moto". Em contrapartida, a ausência dele no ambiente da casa é vista como negativa: "o negativo é a falta dele mesmo, na casa, ainda mais a noite, que tem que ter um homem porque quando tem um homem na casa é outra coisa".

O mesmo foi relatado por Gersilene, que apontou como ponto positivo a garantia de dinheiro para sobreviver durante o ano, independentemente dos bicos no município: "positivo é o dinheirinho que ele guarda. Que ele tem a segurança, tendo serviço ou não, ele tem o dinheirinho dele guardado". Como negativo ela apontou a preocupação causada pela distância, principalmente com a saúde dele: "é muita preocupação dele adoecer lá. Deus dê o livramento, se acontecer alguma coisa".

Entre as chegadas e partidas, a migração acontece como um fenômeno familiar. A migração de Gersílio possibilitou a entrada na educação superior da filha, a melhoria na casa da família. Ao mesmo tempo, provoca nos membros que ficaram a tristeza de não partilhar com ele momentos do convívio. Entre idas e vindas, a família migrante segue a rota conhecida dos migrantes da região: chegar e partir.

O processo do trabalho em Porteirinha é compreendido de acordo com a necessidade da família. Nos relatos, apontam a dificuldade de incorporação no mercado de trabalho local como o principal fator que os levam a procurar pelos trabalhos temporários, uma estratégia para prover recursos. Migram para a reprodução da vida, para manter a família, para suprir necessidades, para adquirirem um produto específico ou trazerem melhorias para a residência.

Identificamos que a baixa escolaridade, a falta de qualificação e especialização, exigidas cada vez mais pelo mercado de trabalho, aliados a perda de território no rural, são alguns dos fatores que dificultam encontrarem emprego nos locais de origem. Por isso, os homens migram para trabalhos que exigem força braçal e resultados imediatos nas atividades que desempenham.

Igual meu marido, não tem estudo, uma pessoa de cor? É difícil encontrar um trabalho. Cadê o serviço aqui? Cadê os empregos que existem aqui dentro de Porteirinha? Não tem! Ainda mais meu marido nessa idade e que não sabe ler, é pior ainda, sabe nem assinar o nome. (Depoimento de Maria do Carmo, 52 anos, concedido em trabalho de campo das autoras em 2017)

As narrativas apresentadas pelas mulheres "ficantes" demonstram as representações criadas a partir da condição de ficar a esperar pelos que migram. No movimento de partir, chegar e voltar, as atividades desempenhadas por quem fica e por quem vai, interferem na estrutura do núcleo familiar, modificando pessoas e lugares. As representações, conforme Magnani (2012: 139) são construídas a partir de experiências individuais decorrentes de uma realidade social comum, que se apresenta sob a forma de relações: família, rede de vizinhança, bairro, categoria profissional, partido, classe social, entre outros. 
De acordo com Paula (2003: 125), “as ações econômicas dos indivíduos baseavam-se também em trocas entre as famílias, parentes, vizinhos, imbricando valores de cooperação, solidariedade e reciprocidade”. Nesse sentido, identificamos a formação de uma rede de solidariedade no grupo social de convivência dos que ficam, pois quando o migrante está fora, a família se ajuda nos momentos de precisão.

Nos relatos das mulheres, identificamos que na ausência física dos homens, elas permanecem para preservarem a casa e garantirem a eles um vínculo com o local de origem que os possibilitem o retorno. Ficam e se dedicam exclusivamente aos cuidados com a educação dos filhos, a alimentação, a limpeza, entre outros afazeres domésticos. Ficam e assumem os papeis desempenhados pelo homem, pai, "chefe de família" durante sua ausência. Mas, nos meses de retorno dos migrantes, retornam à posição de submissão e repassam aos homens as atividades do "chefe da família".

As práticas sociais, os símbolos e discursos se materializam na memória e nas representações sociais das mulheres ao relatarem as migrações dos homens. Relatam os alojamentos, a alimentação, o cotidiano, como se estivessem participando. Mas, ao mesmo tempo, procuram manter uma distância, para evitarem imaginar ou refletir sobre as dificuldades. Ficam, mas vivem o processo migratório de forma intensa e cotidiana.

\section{CONSIDERAÇÕES FINAIS:}

Nosso intuito, neste artigo, foi analisar a migração enquanto um processo social complexo, considerando a configuração da realidade migratória no município estudado, como sendo pautadas nas relações familiares. A pesquisa empírica demonstrou que existe assimetria de gênero no que tange a divisão do trabalho das famílias. Há uma construção social e cultural que determina a posição dos homens e mulheres na vivência da vida coletiva: aos homens é atribuída a função de prover pela família e as mulheres a preservação da casa. Entretanto, essa configuração pode se tornar menos rígida de acordo com a necessidade da família.

Ao estudar a migração através dos relatos de migrantes oriundos do meio rural e das mulheres que esperam o retorno dos mesmos, foi possível a compreensão da dinâmica da realidade migratória das famílias pesquisadas. Em Porteirinha, essa mobilidade acontece de diversas formas e para diferentes destinos. A crise da cultura do algodão, chamado de "ouro branco", significou um período de intensidade desses fluxos. Atualmente, as principais razões apontadas para a migração estão ligadas a não inclusão no mercado de trabalho, ou uma inclusão que proporcione apenas a sobrevivência. 
A migração é uma forma também para suprir novas demandas, como a obtenção de recurso financeiro para a compra de motocicleta, novos eletrodomésticos, da reforma da casa, entre outros desejos familiares de consumo. As migrações se iniciam e, sobretudo, se perpetuam através das redes sociais de informação, onde as relações de parentesco e afinidades proporcionam uma facilidade para a entrada de novos migrantes, como também, confiança para o início dessa experiência.

Migração foi utilizada como categoria analítica, posto que nenhum dos entrevistados se identificam como migrantes e sim como trabalhadores, agricultores rurais, camponeses, pequenos produtores, domésticas. Migrar não é um mero deslocamento geográfico e muito menos uma caminhada individual, mesmo que apenas um migre, o contexto familiar está presente durante todo o processo.

Para expressarem como é esperar pelos que foram, identificamos o termo "falta" como a representação de um sentimento que vai além do significado de saudade, é mais do que a ausência. Reflete a falta do auxílio, da partilha e da compartilha do cotidiano. A tristeza e a insegurança em permanecer sem o ente querido no lugar. A angústia da espera, da incerteza, das preocupações com os perigos dos trabalhos nas fazendas; uma ausência temporal sentida de formas diversas.

A condição de "ficante", atributo das mulheres que permanecem no município e vivem esse movimento de idas e voltas, cria uma representação acerca dos trabalhos desempenhados por elas em decorrência da dinâmica social migratória. As mulheres são atribuídos os trabalhos reprodutivos, o ficar em casa, cuidar dos filhos e realizar o trabalho doméstico, dedicar-se ao lar, sendo pai e mãe. Quando estas vivem o outro lado, o de migrante, percebemos a presença do sentimento de culpa, principalmente do papel de mãe. Sentem-se responsáveis pelos sofrimentos da família, pois muitas vezes precisaram deixar os seus filhos e mesmo conquistando os objetivos materiais, a abertura dos momentos perdidos parece não se fechar.

Identificamos nos relatos a "territorialidade", um sentimento de identificação com o seu meio, impactando na estratégia da família de permanecer no local de origem enquanto outros membros migram, possibilitando o retorno dos migrantes para suas culturas e modos de vida locais. Também identificamos o sonho da migração de todo o núcleo familiar, como um desejo de melhoria de vida, isso associado à saída do lugar de origem. Além disso, com a migração, os que ficam acionam uma rede de solidariedade no grupo social de convivência.

Nossas pesquisas vêm demonstrando e reafirmando como é dinâmico o processo migratório. No contexto Norte Mineiro, marcado de estigmas e políticas públicas excludentes, a migração aparece enquanto condição que ao longo dos anos é um aspecto intrínseco aos modos de vida locais, demonstrando a carência de políticas que proporcionem o ficar. $\mathrm{O}$ processo 
metodológico de pesquisa qualitativa, dentro de um grupo interdisciplinar, vem demonstrando extrema importância, por possibilitar-nos desvelar sobre o que o estar lá representa.

\section{REFERÊNCIAS:}

ANTUNES FILHO, Djalma. Fatores explicativos do declínio da cotonicultura em Porteirinha-MG nos anos 90. 2000. Monografia (Bacharelado em Ciências Econômicas) - Universidade Estadual de Montes Claros, Montes Claros, MG, 2000.

BRANDÃO, Carlos Rodrigues. 2007. Reflexões sobre como fazer trabalho de campo. Revista Sociedade e Cultura, Vol. 10, n.1, p. 11-27.

DAMIANI, Amélia. População e Geografia. São Paulo: Editora Contexto. 2011

FONSECA, Gildette Soares. Migrações da Mesorregião Norte de Minas/MG: análises o censo demográfico de 2010. Tese (Doutorado em Geografia) - Programa de Pós-graduação em Geografia Tratamento da Informação Espacial. Pontifícia Universidade Católica de Minas -PUC-Minas, 2015.

GEERTZ, Clifford. O saber local: Novos ensaios em antropologia interpretativa. Trad. Vera Mello Joscelyne. Rio de Janeiro: Vozes, 1989.

GEERTZ, Clifford. Uma descrição densa: por uma teoria interpretativa da cultura. In: A Interpretação das Culturas. Rio de Janeiro: Zahar, 1989.

IBGE - Instituto Brasileiro de Geografia e Estatística. Censo Demográfico 1991, 2000, 2010. Disponível em: $<$ http://www.ibge.gov.br>. Acesso em: janeiro de 2019.

LITTLE, Paul E. Territórios Sociais e Povos Tradicionais no Brasil: Por uma antropologia da territorialidade. Trabalho apresentado no SIMPÓSIO "NATUREZA E SOCIEDADE: DESAFIOS EPISTEMOLÓGICOS E METODOLÓGICOS PARA A ANTROPOLOGIA”, na 23a Reunião Brasileira de Antropologia, Gramado, RS, 19 de junho de 2002.

MAGNANI, José Guilherme Cantor. De perto e de dentro: notas para uma etnografia urbana. Revista Brasileira de Ciências Sociais, vol.17 n.49, Jun.2012.

MARTINS, José de Souza. O vôo das andorinhas: migrações temporárias no Brasil.In: Não há terra para plantar neste verão. Petrópolis/ Rio de Janeiro: Vozes, 1988.

OLIVEIRA, Palmyra Santos. Porteirinha: memória histórica e genealogia. Belo Horizonte: Editora O Lutador, 2008.

PAULA, Andréa Maria Narciso Rocha de. Integração dos migrantes no mercado de trabalho em Montes Claros, Norte de Minas Gerais: "A Esperança de Melhoria de Vida". 2003. 151 f. Dissertação (Mestrado em Geografia) - Instituto de Geografia, Universidade Federal de Uberlândia, Uberlândia-MG. 2003.

PAULA, Andréa Maria Narciso Rocha de. TRAVESSIAS - Movimentos migratórios em comunidades rurais no Sertão do Norte de Minas Gerais. Tese (doutorado) UFU, 2009.

PIRES, Maria Cecília Cordeiro. PROCESSO MIGRATÓRIO EM PORTEIRINHA-MG: “enquanto eu tiver vida e saúde". Montes Claros: Unimontes/Departamento de Política e Ciências Sociais - DPCS (Monografia de Bacharelado), 2016. 
SALIM, Celso Amorim. Migração: o fato e a controvérsia teórica. ENCONTRO NACIONAL DE ESTUDOS POPULACIONAIS, 8., São Paulo, 1992. Anais... São Paulo: ABEP. 1992.p.119144.v.3.Disponível em: http://abep.org.br. Acesso em: 1 de maio de 2016.

SAYAD, A. A Migração ou os paradoxos da alteridade. São Paulo: Editora da Universidade de São Paulo,1998.

SAYAD, A.O Retorno: elemento constitutivo da condição de migrante. In: Travessia - especial revista do migrante. Publicação do CEM - Ano XIII, número especial, Janeiro/2000.

SOUZA, Carla Nadinne. ENTRE IDAS E VINDAS, A AUSÊNCIA: O Processo Migratório vivido por Mulheres Norte-Mineiras. Montes Claros: Unimontes/Departamento de Política e Ciências Sociais DPCS (Monografia de Bacharelado), 2017.

WOORTMANN, E. Herdeiros parentes e compadre: colonos do sul e sitiantes do nordeste. São Paulo: Hucitec, 1995.

WOORTMANN, Klass. Migração, família e campesinato. In: Camponeses brasileiros: leituras e interpretações clássicas. V.1. Org: Clifford Andew Welch (Et.al). São Paulo: UNESP, Brasília, DF: NEAD, 2009.

\footnotetext{
NOTAS:

${ }^{1}$ Uma primeira versão desse texto foi apresentada no SPG 22 - Investigações em Movimento: Estudos Migratórios e os Desafios da Pesquisa de Campo, no 42 ${ }^{\circ}$ Encontro Anual da ANPOCS em Outubro de 2018.

${ }^{2}$ Grupo de estudos e pesquisas do São Francisco - OPARÁ/MUTUM, CEPEx 96/2011.Reconhecido na Unimontes e no CNPq.

${ }^{3}$ Projeto "Sair, Ficar, Voltar: um estudo sobre migrações temporárias no sertão Norte-Mineiro" - aprovado no Comitê de Ética e Pesquisa pela portaria CEPEx 074/2015, 2014-2016, Unimontes/Fapemig.

${ }^{4}$ Projeto"Do Sertão para outros mundos": As redes de relações sociais nos processos migratórios para o trabalho do/no Norte de Minas Gerais - aprovado no Comitê de Ética e Pesquisa pela portaria CEPEx 034/2017, 2016-atual. Unimontes/Fapemig.

${ }^{5}$ Para Geertz (1989) o trabalho etnográfico é realizado em dois momentos distintos, o estar lá, quando o pesquisador está no campo junto aos "nativos" e desenvolve a coleta de dados e o estar aqui, quando volta para a academia, no momento de interpretação e escrita.

${ }^{6}$ As sementes crioulas são um tipo antigo, que guarda um repertório de seleção natural de milhares de anos. Adaptadas aos ambientes locais, são mais resistentes e menos dependentes de substâncias sintéticas. Elas contribuem para a diversidade alimentar e para a biodiversidade dos sistemas de produção. São resultado, também, do trabalho de gerações de agricultores que selecionaram, multiplicaram e as compartilharam. Disponível em: http://teiaorganica.com.br/blog/tag/sementes-crioulas/
}

\section{AUTORES:}

Andréa Maria Narciso Rocha de Paula

Doutora em Geografia pelo Programa de Pós-Graduação em Geografia-PPGEO/IG/UFU. Professora da UNIMONTES no curso de Ciências Sociais, no Programa de Pós-Graduação em Desenvolvimento Social - PPGDS e no Programa de Pós-Graduação em Sociedade Ambiente e Território - PPGSAT, associado UNIMONTES e UFMG.

\section{Maria Cecília Cordeiro Pires \\ Mestre em Desenvolvimento Social pelo Programa de Pós-Graduação em Desenvolvimento Social - PPGDS/UNIMONTES, graduada em Ciências Sociais pela mesma Universidade. Integrante do Grupo OPARÁ/MUTUM.}




\section{Carla Nadinne Souza}

Mestranda pelo Programa de Pós-Graduação em Desenvolvimento Social - PPGDS/UNIMONTES, graduada em Ciências Sociais pela mesma Universidade. Integrante do Grupo OPARÁ/MUTUM. Bolsista CAPES. 